\title{
A LUTA PELA EDUCAÇÃO DO CAMPO
}

Luana Reverti de Araújo Silva ${ }^{1}$

Kellynay Lima Souza ${ }^{2}$

\begin{abstract}
RESUMO
Este trabalho visa discutir brevemente sobre a Educação do Campo, descrevendo seu contexto histórico e a legislação que a ampara e diz como deve ser ofertada. Sabe-se que a Educação do Campo surge como expectativa de uma proposta educativa cuja base seja a cultura dos sujeitos do campo em prol de uma sociedade justa que reconheça seus direitos. Buscou-se, através da pesquisa bibliográfica, apresentar e discutir autores renomados no tema, como Almeida (2006) e Caldart (2004). Observou-se que a legislação vigente é fruto de muitas lutas mas só sua existência não garante a oferta, principalmente em contextos urbanos. Assim, considera-se esse trabalho relevante, pois sinaliza a luta pela Educação do Campo e a necessidade de garantir que a legislação saia do papel e permita que a escola reconheça 0 cotidiano do aluno do campo, valorizando seu contexto e modo de vida.
\end{abstract}

Palavras-chave: Educação do Campo. Legislação. Currículo.

1 Mestranda em Educação pela Faculdade interamericana de Ciencias Sociales. Asunción-PY. Contatos: E-mail - revertiluana4@gmail.com (77) 991318876

2 Mestranda em Educação pela Faculdade interamericana de Ciencias Sociales. Asunción-PY. Contatos: E-mail - kellynay@bol.com.br (77) 991099551 


\section{INTRODUÇÃO}

A educação escolar constitui um direito social e, portanto, cabe ao Estado garantir condições e recursos para a sua efetivação. Entretanto, é perceptível a desigualdade entre os níveis de escolaridade dos indivíduos que vivem no campo e os que vivem nas cidades. Em todos os indicadores sociais e educacionais, as populações do campo estão em desvantagem.

Mesmo sabendo que é obrigação do Estado oferecer educação escolar às crianças e aos jovens que moram no meio rural, estes passam por dificuldades, pois em alguns casos são obrigados a estudar em uma escola na área urbana, distante de seus familiares e de sua comunidade.

Nesse contexto, muitas vezes necessitam fazer uso do transporte escolar, com longas e cansativas distâncias, ambiente escolar estranho, problema de relacionamento e adaptação ao novo contexto, além de serem obrigados a conviver com a inadequação do material didático-pedagógico que não se faz referência ao campo ou, quando faz, traz o ambiente e suas populações representadas de forma estereotipada e preconceituosa.

No Brasil, a Educação do Campo tem sido resultado de lutas e interesses. Para Melo (2011), esses conflitos não têm sido unicamente educacionais, mas também resultados de um conturbado processo social, histórico, econômico, político e cultural desempenhado em nosso país.

No IBGE, a Educação do Campo é definida atualmente pela origem do aluno e as características peculiares do lugar que o identifica. Por exemplo: se um aluno é morador do campo e se desloca para estudar numa escola urbana, essa situação não o torna um aluno urbano, mas o identifica como sendo um aluno da Educação do Campo.

Arroyo, Caldart e Molina (2008) defendem que, quanto mais se gritam as especificidades da Educação do Campo, mais urgente se torna a necessidade da afirmação de um projeto social por uma Educação do Campo que garanta a inserção do campo e a participação do rural, juntamente com o urbano, no conjunto da sociedade. 
Dessa forma, faz-se necessário enfatizar que os sujeitos que vivem e trabalham no campo são portadores dos mesmos direitos dos que vivem e trabalham na área urbana $e$, dentre outros, o direito a uma educação de qualidade, que respeite suas origens, contribua positivamente para 0 desenvolvimento desses cidadãos que já foram, muitas vezes, excluídos, perseguidos e desprestigiados.

Vale ressaltar que não se trata de dicotomizar a relação campo-cidade, supervalorizando os saberes dos educandos oriundos das escolas do campo e menosprezando os das escolas urbanas, ou vice-versa, mas sim, de reconhecer a necessidade de implantar e implementar as legislações federal e estadual.

Diante do exposto, este trabalho visa discutir sobre a Educação do Campo, descrevendo seu contexto histórico e a legislação que a ampara e diz como deve ser ofertada.

Para tanto, recorremos à pesquisa bibliográfica, cujo objetivo é reunir as informações e dados expostos por vários autores que servirão de base para a construção da investigação proposta.

\section{AGRICULTURA NO BRASIL}

A questão agrária brasileira tem a sua origem mais remota na forma como se deu a ocupação do território nacional a partir do período colonial. $\mathrm{O}$ processo de colonização baseou-se no estabelecimento de grandes unidades agrícolas voltadas para o abastecimento do mercado europeu, criando uma estrutura fundiária extremamente injusta.

A concentração de terras nas mãos de sesmeiros, e depois de grandes proprietários, impôs aos camponeses uma posição de subordinação social, econômica e política desde o início. Contudo, as formas de dominação a que essa classe tem sido submetida variam de acordo com as diferentes situações encontradas e, também, ao longo do tempo.

Mesmo sem o devido registro, sabe-se que a vocação agrícola do Brasil existe mesmo antes do seu descobrimento, em 1500. Todavia, a formação da agricultura brasileira deveu-se, sobretudo, à ação dos colonizadores, que trouxeram espécies animais e vegetais, e que souberam, juntamente com os 
povos aqui existentes ou que aqui foram forçados a trabalhar, desenvolver uma riquíssima atividade agroprodutiva nesta região tropical.

Vale lembrar ainda que a concentração de terras no Brasil originou-se com a primeira divisão territorial implementada pela metrópole portuguesa durante o período Colonial, quando o rei de Portugal dividiu grande parte do então território da Colônia em 14 partes - as capitanias hereditárias.

O sistema de capitanias hereditárias concedia terras e vantagens aos donatários - aqueles que eram favorecidos pela doação. Era como dar amplos poderes a quem se dispusesse a investir dinheiro e pessoal no estabelecimento de núcleos de povoamento. Esses donatários tinham regalias como o direito de nomear juízes e autoridades administrativas, receber impostos, distribuir terras, entre outros.

Como o cultivo das terras doadas só era viável economicamente em grandes plantações, as doações feitas a quem se dispusesse a explorá-las eram generosas, pois não havia recursos para investir na melhoria de pequenas plantações. Assim, a estrutura fundiária no país já se iniciava de modo concentrado.

No Brasil, a colonização portuguesa baseou-se, desde os seus primórdios, no desenvolvimento de uma agricultura comercial de exportação. A produção de açúcar para o mercado europeu em expansão, no século XVI, estabeleceu uma economia de "plantation" que subsiste, embora com uma forma diferente, até o presente.

A força de trabalho da agricultura foi originalmente fornecida por grandes contingentes de escravos africanos e, mais tarde, por homens livres vinculados à "plantation", por toda uma gama de contratos de arrendamento.

Eric Wolf (apud NEVES \& SILVA 2008), por exemplo, define plantation por um modelo geral de organização da produção, cujas transformações foram sistematizadas por ele segundo as condições de vínculo da força de trabalho escrava ou livre. Foi, portanto, o cultivo de cana-de-açúcar que impulsionou a agricultura colonial.

As grandes monoculturas brasileiras que se formaram a partir de então estavam associadas ao comércio exterior e, de acordo com o pacto colonial que, na Colônia, produziam e exportavam matérias-primas e produtos para a Metrópole com o emprego do trabalho escravo. 
Na produção colonial, que tinha seu sustentáculo na expansão dos 4 mercados, ou seja, num sistema mercantil voltado para a monocultura da exportação, o escravo era renda capitalizada. Dessa feita, emerge a contradição entre produção direta dos meios de subsistência e produção para o mercado. Portanto, cabiam ao escravo as atividades voltadas ao mercado, sobrando aos homens pobres livres as culturas subsidiárias (...) (ALMEIDA, 2006. p. 102).

Com a perspectiva do fim da escravidão, foi criado um mecanismo para impedir a livre posse da terra pelos pobres e escravos libertos. A Coroa preocupou-se em legislar sobre a propriedade privada no campo ao regularizar a compra e a venda de terras, por meio de pagamento em dinheiro, e o novo tipo de mão de obra empregado no cultivo: assalariada.

Sobre o nosso país, MARTINS (1986, p. 17), afirma que

\begin{abstract}
No nosso caso, o avanço do capitalismo não dependeu da abertura de um espaço livre à ocupação de capital. $O$ trabalhador já era expropriado. Foi o próprio capital que, com a crise do trabalho escravo, instituiu a apropriação camponesa da terra; uma contradição evidente num momento em que o capital necessitava de força de trabalho, de trabalhadores destituídos de sua própria força de trabalho. Por essa razão, o nosso camponês não é um enraizado. Ao contrário, o camponês brasileiro é desenraizado, é migrante, é itinerante.
\end{abstract}

Sancionada após a proibição do tráfico de escravos e com a necessidade de se assegurar uma oferta de mão-de-obra livre, a Lei de Terras foi promulgada em 1850. Essa lei proibia a aquisição de terras por qualquer outro meio que não fosse a compra; logo, as doações foram proibidas.

A lei garantiu ainda a posse de terras a antigos proprietários e posseiros, restringindo-a a imigrantes e ex-escravizados. São, assim, redefinidas as condições de existência do campesinato que, a partir daí, fica impedido formalmente de se estabelecer na terra por meio da posse. Inaugura-se a forma de propriedade capitalista da terra.

Antes "posse" e "sesmaria" correspondiam a lógicas distintas e combinadas, podendo a concessão de sesmaria ocorrer em terras já tomadas por posseiros, problema que se resolvia pela superioridade jurídica da sesmaria e pelo vínculo de dependência que tal superioridade supunha do posseiro em relação ao sesmeiro. Agora o espaço camponês passa a ser um e o espaço do fazendeiro passa a ser outro (MARTINS, 1981, p. 43). 
O processo histórico é constituído pelas relações sociais e pelos antagonismos de classe. Assim, para Martins (1981), o campesinato brasileiro é resultado e consequência do próprio desenvolvimento capitalista no campo, e considera algumas questões como a sua resistência e formas de luta.

Exemplos de resistência e luta camponesa estão presentes em movimentos como a Guerra de Canudos (1893), no interior da Bahia, e a Guerra do Contestado (1908), na fronteira entre Paraná e Santa Catarina, nas quais milhares de camponeses se agruparam para defender suas terras e organizar resistências.

Por volta de 1945, começaram a se organizar as Ligas Camponesas, que lutavam por uma reforma agrária ampla. A estratégia utilizada foi a ocupação de terras. Esse movimento durou décadas, até ser violentamente reprimido e extinto após o golpe militar, em 1964. Esses conflitos, em muitos casos, são resolvidos de maneira brutal, transformados em massacres contra os camponeses.

Exemplo disso são os indígenas que estão há mais de quinhentos anos lutando, fugindo, morrendo e resistindo numa luta contra o capital, representado por jesuítas, por senhores de engenho e, hoje, por grileiros, madeireiros, latifundiários, com o apoio do Estado.

A história do campesinato no Brasil é marcada desde muito cedo pela luta para se reproduzir no seio da sociedade, os quais se destaca a dos grandes proprietários de terra, e pela ação estratégica do Estado que visa enquadrá-lo em seu projeto de desenvolvimento excludente a partir da adoção de uma diversidade de políticas.

Uma ação estratégica do Estado foi que, somente em 1964, com o Estatuto da Terra, o governo e a sociedade passaram a discutir questões relacionadas à reforma agrária. Esta, entendida aqui como uma mudança na estrutura da propriedade da terra em determinado local.

O tema foi incluído na Constituição Federal, em 1988, garantindo o direito à terra e à desapropriação dos latifúndios improdutivos para fins de reforma agrária. No entanto, as divergências sobre a forma como a terra devia ser distribuída e sobre as propriedades que podiam ser desapropriadas para 
esse fim geraram (e tem gerado) inúmeros conflitos de interesse e violência no campo.

\begin{abstract}
É evidente que há no Brasil uma questão agrária. Mas, uma questão agrária que parece distanciada das condições históricas de sua solução definitiva, porque esta sociedade perdeu as poucas oportunidades históricas que teve para resolvê-la. Temos uma questão agrária administrada, sob controle, em grande parte porque, mesmo na máxima exacerbação da luta dos que reivindicam a reforma agrária, ela não se revela comprometedora para o funcionamento dos diferentes níveis do sistema econômico e do sistema político. Ela tende a aparecer residualmente como um problema social não referido a uma questão estrutural (MARTINS, 2000, p.102).
\end{abstract}

Em linhas gerais, pode-se considerar a reforma agrária a partir de dois pontos de vista. O primeiro, mais distributivo, tem como objetivo o aumento do número de propriedades e proprietários rurais. O segundo, considera a eficiência dos métodos de produção e o aumento da produtividade.

Esses modelos de distribuição variam desde a coletivização do uso da terra e a organização em cooperativas até a posse comercial do terreno, em que predominam as leis de mercado praticamente sem intervenção do Estado. O jogo de forças entre os defensores de cada proposta forma o contexto das lutas no campo no Brasil.

A redemocratização e as discussões da nova Constituição, na década de 1980, possibilitaram a reorganização dos movimentos sociais que reivindicaram o acesso à terra.

Desse modo, o principal movimento de luta pela reforma agrária no Brasil é o Movimento dos Trabalhadores Rurais Sem Terra (MST). Uma vertente progressista da Igreja Católica, a Teologia da Libertação, e alguns partidos políticos foram os principais fomentadores do MST.

Nesse sentido, a organização agrária atual assemelha-se muito àquela do período Colonial: predominância de grandes propriedades com monocultura voltada para a exportação. Assim, é perceptível que a organização socioespacial do campo, no Brasil, estabeleceu-se com base nas desigualdades de uso, ocupação e distribuição de terras.

Mesmo após a Independência e a Proclamação da República, os proprietários de terra muitas vezes exerceram um poder paralelo ao poder do 
Estado, sendo marcante na vida política nacional. Para isso, relembramos que a Lei de Terras - de 1850 até o Estatuto da Terra 1964 - assegurou e legitimou a propriedade de terras, especialmente dos latifundiários.

Na República Velha (1889-1930), mais de três quartos da população viviam no campo, em sua maioria nas terras dos fazendeiros. Em época de eleição, as pessoas, por gratidão, pressão política ou até mesmo violência, eram levadas a votar nos candidatos indicados pelo coronel da região.

Esse tipo de relação, conhecida como coronelismo, perdura até hoje. Ela caracteriza-se pela associação direta entre a propriedade das terras e o poder político e pela garantia de privilégios aos coronéis; como a construção de açudes em propriedades privadas, com mão de obra e recursos públicos, e o controle sobre serviços de saúde e transportes.

Nesse contexto, a rede de clientelismo (prestação de favores políticos em troca de votos) atinge as esferas estadual e federal. Deputados eleitos com a ajuda dos coronéis apresentam pedidos de verbas do orçamento para realizar melhorias em suas áreas de atuação. Assim, serviços públicos gratuitos, de obrigação do Estado, são apresentados como se fossem presentes obtidos pelo prestígio pessoal do coronel, o padrinho.

Atualmente, o espaço rural brasileiro apresenta enorme diversidade e complexidade, com aspectos muito contrastantes. O meio rural convive com situações de violência e/ou relações de trabalho de extrema exploração, mas também com modernizações ligadas às atividades econômicas (agronegócio e agricultura familiar tecnicizada) e aos aspectos sociais, como assentamentos bem-sucedidos e experiências de agricultura orgânica.

Com isso, um dos contrastes notáveis no país é a presença da agricultura moderna ao lado da agricultura tradicional. $O$ alto grau de tecnologia e de inovações técnicas em algumas propriedades contrapõe-se à precariedade e à falta de recursos em outras. Podem ser destacados, também, avanços ligados aos aspectos sociais: as experiências de sucesso em assentamentos, o crescimento da agropecuária orgânica, as melhorias na área da educação e a valorização da cultura no campo.

Há ainda os trabalhadores rurais sem-terra, que se organizam em movimentos sociais em busca de melhores condições de vida, e as 
comunidades indígenas e quilombolas, que praticam agricultura de subsistência.

Além de todas essas questões, vale observar ainda o difícil acesso à rede de saneamento básico e as relações ilegais de trabalho. Situação especialmente grave uma vez que, em muitas regiões do país, há permanência do trabalho escravo e semiescravo.

O conhecimento acerca das relações de poder no campo permite compreender a dificuldade de implementação de mudanças na estrutura fundiária do país.

\section{CAMPESINATO BRASILEIRO E A EDUCAÇÃO A ELE DESTINADA}

O processo de formação do campesinato brasileiro é marcado por se diferencia do europeu. Para Almeida (2006, p. 104),

O campesinato brasileiro tradicional foi concebido às margens do sistema escravista latifundiário exportador. A ele não foi dado o direito à terra, restando a posse como alternativa. No entanto, a concessão da sesmaria tinha precedência legal sobre a terra dos posseiros, cabendo ao fazendeiro decidir sobre sua permanência ou não na situação de agregado.

Embora a origem do conceito de camponês esteja relacionada à realidade da Idade Média Europeia, a formação do campesinato brasileiro guarda as suas especificidades. Aqui, o campesinato é criado no seio de uma sociedade situada na periferia do capitalismo e à margem do latifúndio escravista.

Assim, o conceito de camponês adquire lugar de destaque nas ciências sociais brasileiras nos anos 50 ao mesmo tempo em que se afirma como identidade política em nível nacional. Quando a grande concentração de terras e a extrema desigualdade social se tornam mais evidentes com as mudanças verificadas nas relações de trabalho e aparecem como fundamentos da questão agrária brasileira, emerge o momento das "Ligas Camponesas".

Até então, o camponês recebia denominações locais próprias conforme a sua história e sua região de origem, como: caipira em São Paulo, Minas Gerais e Goiás; caiçara no litoral paulista; colono ou caboclo no Sul - 
dependendo de sua origem, se imigrante ou não. Isso também acontecia com os grandes proprietários de terra, que eram conhecidos como estancieiros, senhores de engenho etc.

Em decorrência do mesmo processo que deu sentido ao conceito de camponês, é definido o conceito de latifundiário, o seu par contraditório. Assim, eles aparecem como conceitos-síntese, ou categorias-analíticas, que remetem a situações de classe e que estão enraizados numa longa história de lutas.

O campesinato se refere a uma diversidade de formas sociais baseadas na relação de trabalho familiar e formas distintas de acesso à terra, como 0 posseiro, o parceiro, o foreiro, o arrendatário, o pequeno proprietário etc. A centralidade do papel da família na organização da produção e na constituição de seu modo de vida, juntamente com o trabalho na terra, constituem os elementos comuns a todas essas formas sociais.

Assim, a concepção de camponês não está relacionada somente às atividades agrárias, mas ao conjunto de características que determinam o modo de vida, a relação com a terra-trabalho, a importância da família, a sustentabilidade. Enfim, ao equilíbrio entre terra-trabalho-renda como forma de manutenção e reprodução da família e, consequentemente, do campesinato.

Wanderley (1996, p. 03), ao discutir sobre as raízes históricas do campesinato, compreende o campesinato tradicional como "uma das formas sociais de agricultura familiar, uma vez que ela se funda sobre a relação indicada entre propriedade, trabalho e família".

Portanto, é consenso essa relação do camponês com o significado material, afetivo, simbólico da propriedade da terra, já que esta lhe dá autonomia diante de outros modos de produção e é fruto do trinômio patrãoempregado-consumidor.

Nesse sentido, a luta dos movimentos sociais no campo é pela aceleração do processo de reforma agrária e pela ampliação dos benefícios aos assentados, como assistência técnicas e crédito agrícola. Além da luta pela posse da terra, esses movimentos criam propostas de educação e de participação social para os moradores do campo e para os assentados que sempre foram consideradas sem cultura, sem educação e, pior, como se servissem apenas para trabalhar no campo, e que, portanto, não precisariam de uma educação formal. 
Todavia, existem legislações que garantem o direito à educação de qualidade à população camponesa e que ressaltam os direitos educacionais dessa parcela da população que possui necessidades e interesses específicos que diferenciam da população urbana.

Durante décadas, a formação destinada às classes populares do campo vinculou-se a um modelo "importado" da educação urbana. Esse tratamento teve um fundo de descaso e subordinação dos valores presentes no meio rural e marcava uma inferioridade quando comparado ao espaço urbano.

O campo encontrava-se estigmatizado na sociedade brasileira, e os preconceitos, estereótipos e outras conotações multiplicavam-se cotidianamente. Essa constatação foi mencionada por Leite (1999, p. 14) na seguinte observação:

\begin{abstract}
A educação rural no Brasil, por motivos socioculturais, sempre foi relegada a planos inferiores e teve por retaguarda ideológica 0 elitismo, acentuado no processo educacional aqui instalado pelos jesuítas e a interpretação político-ideológica da oligarquia agrária, conhecida popularmente na expressão: "gente da roça não carece de estudos". Isso é coisa de gente da cidade. (anônimo).
\end{abstract}

Por outro lado, os movimentos sociais defendem que o campo é mais que uma concentração espacial geográfica. É o cenário de uma série de lutas e embates políticos. É ponto de partida para uma série de reflexões sociais. É espaço culturalmente próprio, detentor de tradições, místicas e costumes singulares.

O homem e a mulher do campo, nesse contexto, são sujeitos historicamente construídos a partir de determinadas sínteses sociais específicas e com dimensões diferenciadas em relação aos grandes centros urbanos. Assumir essa premissa pressupõe corroborar com a afirmação da inadequação e insuficiência da extensão da escola urbana para o campo.

Não se pode esquecer que o direito à educação no Brasil derivou-se das lutas e conquistas democráticas ao longo dos últimos anos. Porém, tanto quanto um direito, a educação é um dever. Dever do Estado. E, como tal, emergem obrigações que devem ser respeitadas e protegidas, inclusive por meio de lei. Apesar de o Brasil ser um país de origem agrária, a educação do 
campo não teve lugar e nem sequer foi lembrada nos textos constitucionais até 1891, evidenciando o descaso com essa parcela da população.

Esse panorama deixou como herança um quadro de precariedade no funcionamento da escola do campo em relação ao capital humano disponível para o trabalho pedagógico; uma infraestrutura e espaços físicos inadequados; escolas mal distribuídas geograficamente; condições trabalhistas precárias e baixos salários; ausência de formação inicial e continuada adequada ao exercício docente no campo; e uma organização curricular descontextualizada com a realidade da vida campesina.

Inicialmente, ofertada para a população campesina,

a educação rural era predominantemente vista como algo que atendia a uma classe da população que vivia num atraso tecnológico, subordinado, a serviço da população dos centros urbanos (ROSA; CAETANO, 2008, p. 23).

Esse tipo de educação predominou até a segunda metade do século $X X$, em que não se havia uma preocupação com a cultura e costumes do homem do campo. Dessa forma, a educação voltada para as pessoas do campo não condizia com a realidade na qual a escola estava inserida.

O único objetivo da educação rural era formar pessoas para o mercado de trabalho urbano; fato que contribuiu muito para o êxodo rural. Tudo isso por conta da falta de valorização da cultura camponesa, já que a maioria dos materiais didáticos eram voltados para a realidade urbana, ou seja, uma pedagogia distanciada da realidade camponesa, sem qualquer significado para os alunos do campo (ROSA; CAETANO, 2008, p. 28).

As mudanças começam a aparecer somente a partir da segunda metade do século XX. Eram reivindicações de movimentos sociais e da sociedade civil que desejavam uma educação voltada para os interesses e necessidades da população do campo, bem como uma educação que valorizasse a cultura e a identidade dessa população.

Percebe-se que, com tais movimentos, havia o desejo de uma educação inclusiva e autônoma. 
Importante também evidenciar que até a década de 1950, não havia um investimento para a educação do campo, fato que comprometia sensivelmente a qualidade educacional, bem como 0 desenvolvimento dessas escolas rurais no mesmo patamar de igualdade que as escolas urbanas. Não havia uma preocupação com o homem do campo e seu desenvolvimento, e sim, a escola rural era identificada e evidenciada pela sua localidade geográfica e não pelas pessoas que lá viviam (ROSA; CAETANO, 2008, pp. 28-29).

A mudança desse contexto desolador teve início apenas a partir de 1980, quando a sociedade, articulada com movimentos sociais em favor da educação popular, incluiu a educação do campo dentro de suas expressividades para a redemocratização do país. Esse compromisso foi reforçado na Constituição Brasileira de 1988, de promoção de educação multicultural que respeita as particularidades regionais.

A partir da década de 1990, o panorama da educação começa a dar sinais de mudança, encadeado pela pressão dos movimentos sociais e sindicais, em favor da construção de políticas públicas para a população do campo. Propôs-se, ao poder público, uma educação significativa, desvinculada do modelo urbano-industrial capitalista, e uma estrutura agrária que usa a terra apenas como instrumento de exploração, subordinada ao modelo de acumulação do capital.

\subsection{Educação Rural x Educação do Campo}

A população do campo, assim como todas as questões voltadas ao meio rural, por muito tempo, foi deixada de lado nas políticas públicas. Ghedin (2012) afirma que as lutas por uma educação do campo ganham um novo cenário a partir de 1990.

Camponeses e movimentos sociais reuniram-se para discutir, propor e reivindicar do poder público uma política de educação para os povos que vivem no campo e os que são do campo.

A primeira coisa a se fazer, em meio a esse cenário de lutas por uma Educação do Campo com qualidade, seria diferenciar educação do campo e educação rural que, conforme Caldart (2012, p. 259),

A educação do campo nomeia um fenômeno de realidade brasileira atual, protagonizado pelos trabalhadores do campo e suas 
organizações, que visa incidir sobre a política da educação desde os interesses sociais das comunidades camponesas. Os objetivos e sujeitos a remeterem às questões do trabalho, da cultura, do conhecimento e das lutas sociais dos camponeses e ao debate (de classes) entre projetos de campo e entre lógicas de agricultura que têm implicações no projeto de país e de sociedade e nas concepções de políticas públicas, de educação e de formação humana.

A Educação do Campo procura construir um terreno sólido, a partir de um projeto político pedagógico construído pelos próprios sujeitos. Nesse âmbito, a escola almeja, além de formar alunos, uma educação que contribua com a vida do aluno no meio em que se insere fora do espaço escolar.

Em relação à Educação Rural, Caldart (2012, p. 295) explica que

\begin{abstract}
Trata-se dos camponeses, ou seja, daqueles que residem e trabalham nas zonas rurais e recebem o menor rendimento pelo seu trabalho. Para este sujeito, quando existe uma escola na área em que vivem, é oferecida uma educação da mesma modalidade da que é oferecida às populações que residem e trabalham nas áreas urbanas, não havendo, de acordo com os autores, nenhuma tentativa de adequar a escola rural às características dos camponeses ou dos seus filhos, quando estes a frequentam.
\end{abstract}

Assim, é perceptível a significativa diferença entre as duas concepções de educação. A primeira tende a potencializar seus alunos a partir do meio em que vivem; enquanto a segunda apenas contribui para reprodução do conjunto de saberes aos alunos, sem a crítica devida e sem levar em consideração o espaço onde vivem e suas peculiaridades

\title{
4 EDUCAÇÃO DO CAMPO A PARTIR DOS MARCOS LEGAIS
}

Um avanço significativo em relação à educação do campo ocorreu em 1996 com a promulgação da nova Lei de Diretrizes e Bases da Educação LDB/96. Esta delineou as principais ideias que norteiam a educação, determinando legalmente como deve ser a metodologia, o currículo, a organização das escolas situadas no campo, bem como questões envolvendo o calendário escolar que diverge do calendário das escolas do meio urbano por conta de situações climáticas e fases do ciclo agrícola.

O artigo 28 da LDB/96 (BRASIL, 1996, p. 28) determina que: 
Art. 28. Na oferta de educação básica para a população rural, os sistemas de ensino promoverão as adaptações necessárias à sua adequação às peculiaridades da vida rural e de cada região, especialmente: I - conteúdos curriculares e metodologias apropriadas às reais necessidades e interesses dos alunos da zona rural; II organização escolar própria, incluindo adequação do calendário escolar às fases do ciclo agrícola e às condições climáticas; III adequação à natureza do trabalho na zona rural. (Incluído pela Lei no 12.960, de 2014).

Dessa forma, a Lei possibilitou que a educação do campo fosse organizada de acordo com as necessidades e especificidades da cultura camponesa. Considerou, portanto, as diferenças regionais existentes no país, as quais deverão ser levadas em conta no momento do processo de ensino e aprendizagem dos alunos, buscando práticas educativas e pedagógicas que estejam de acordo com a realidade da população camponesa, bem como que levem em conta a cultura e as tradições das pessoas que vivem no âmbito rural.

Observa-se uma educação que surge em resposta aos movimentos sociais do campo que sempre buscavam uma educação condizente com a vida e os hábitos dos alunos da zona rural.

Assim, educação do campo é aquela voltada para um público alvo específico e que, portanto, é necessário que seja fornecida nas escolas situadas no campo - ou na cidade; desde que atendam à maioria de alunos campesinos - e considere a cultura e a identidade das pessoas que lá vivem. É preciso, também, que valorizem e enriqueçam ainda mais essa cultura camponesa que, historicamente, foi e ainda é menosprezada e subjugada pelas pessoas do meio urbano.

Foi só a partir da realização da I Conferência Nacional por uma educação do campo, em 1998, que

A expressão campo passa a substituir o termo rural. Entende-se que, em tempos de modernização, com esta expressão campo, há uma abrangência maior de sociedades diversas que habitam as regiões do país que não se dizem urbanas. Com implantação do conceito "educação do campo", ocorre uma inclusão e consequente valorização das pessoas que habitam o meio rural, oferecendo-lhes oportunidade de participarem, por meio de suas experiências, de programas produtivos, atuando na sociedade de forma igualitária, estabelecendo uma relação harmoniosa entre produção, terra e seres humanos, com relações sociais democráticas e solidárias (ROSA; CAETANO, 2008, p. 23). 
A mudança de nomenclatura reforça a necessidade de um olhar diferenciado, que reconheça a diversidade existente no espaço rural e valorize cada cidadão camponês ali residente, pois o princípio da educação do campo é a inclusão e o reconhecimento dos sujeitos do campo como cidadãos do processo educacional e de sua própria identidade. Assim, a essência pedagógica e metodológica deve ser específica para pessoas do campo em seu espaço cultural, sem abrir mão de sua pluralidade como fonte de conhecimento em diversas áreas.

Arroyo \& Fernandes (1999), na Articulação Nacional Por Uma Educação Básica do Campo, enfatizaram que o termo "campo" é resultado de uma nomenclatura proclamada pelos movimentos sociais e deve ser adotada pelas instâncias governamentais e suas políticas públicas educacionais mesmo quando ainda relutantemente pronunciada em alguns universos acadêmicos de estudos rurais.

Historicamente, percebemos que a criação do conceito de educação escolar, no meio rural, esteve vinculada à educação "no" campo, descontextualizada, elitista e oferecida para uma minoria da população brasileira. Porém, na atual conjuntura, a educação "do" campo, estreita laços com inúmeros projetos democráticos que contribuem para o fortalecimento da educação popular.

A superação da educação rural, vista apenas como uma formação mercadológica, e a recente concepção de educação do campo foram constituídas por uma longa trajetória de lutas e discussões no interior dos movimentos sociais, das entidades, representações civis, sociais e dos sujeitos do campo.

A mudança na compreensão desse conceito reflete muito mais do que uma simples nomenclatura. Ela é inevitavelmente o resultado de um olhar politicamente referendado na busca pelos direitos sociais e na defesa da seguinte trilogia: educação, sociedade e desenvolvimento. Fatores esses indispensáveis para a concretização de projetos político-pedagógicos que busquem encarar a realidade e atender às necessidades das populações do campo. 
Caldart et al (2012, p. 295) descreve uma definição para educação do campo:

A Educação do Campo nomeia um fenômeno da realidade brasileira atual, protagonizado pelos trabalhadores do campo e suas organizações, que visa incidir sobre a política de educação desde os interesses sociais das comunidades camponesas. Objetivo e sujeitos a remetem às questões do trabalho, da cultura, do conhecimento e das lutas sociais dos camponeses e ao embate (de classe) entre projetos de campo e entre lógicas de agricultura que têm implicações no projeto de país e de sociedade e nas concepções de política pública, de educação e de formação humana.

A educação do campo é, portanto, uma proposta abrangente que visa à formação do homem do campo e à valorização no que diz respeito ao espaço, tempo e modelo de currículo, que mobilize as atividades campesinas abrangentes a toda a família, bem como as estratégias para o desenvolvimento sustentável.

\begin{abstract}
Esta visão do campo como espaço que tem suas particularidades e que é ao mesmo tempo um campo de possibilidades da relação dos seres humanos com a produção das condições de sua existência social, confere à Educação do Campo o papel de fomentar reflexões sobre um novo projeto de desenvolvimento e o papel do campo neste projeto. Também o papel de fortalecer a identidade e a autonomia das populações do campo e ajudar o povo brasileiro a compreender que não há uma hierarquia, mas uma complementaridade: cidade não vive sem campo que não vive sem cidade (ARROYO, CALDART e MOLINA, 2005, p. 15).
\end{abstract}

Segundo Fernandes \& Molina (2004), o campo é um local de particularidades e matrizes culturais. É um espaço de possibilidades políticas, formação crítica, resistência, mística, identidades, histórias e produção das condições de existência social. Assim, cabe à educação do campo o papel de fomentar reflexões que acumulem forças e produção de saberes.

Outro documento importante, instituído pela Resolução CNE/CEB ํo. . 1, de 3 de abril de 2002, são as Diretrizes Operacionais para a Educação Básica nas Escolas do Campo.

A implementação dessas diretrizes foi uma reivindicação histórica dos movimentos sociais do campo. Suas orientações referem-se às responsabilidades dos sistemas de ensino com o atendimento escolar sob a 
ótica do direito; implica respeito às diferenças e à política de igualdade, tratando a qualidade da educação escolar na perspectiva de inclusão.

Assim, as Diretrizes resultam da luta pela educação de qualidade social para todos os povos que vivem no e do campo, com identidades diversas, tais como pequenos agricultores, sem terra, povos da floresta, pescadores, ribeirinhos, quilombolas, extrativistas e assalariados rurais.

Portanto, as diretrizes revelam um objetivo maior em relação à inclusão da educação em todos os níveis. Buscam, também, uma integração da educação escolar com as experiências cotidianas do educando, de acordo com a sua origem, os seus costumes e os seus valores, numa perspectiva integradora escola/campo.

Nesse sentido, a escola deve contemplar a identidade do campo e reconhecer a heterogeneidade dos sujeitos sociais que ali vivem e/ou trabalham e seus diferentes modos de vida. Deve, sobretudo, assumir a educação como força mobilizadora que faz emergir o compromisso coletivo com as estratégias de desenvolvimento sustentável e de inclusão social e política, oportunizando o acesso aos conhecimentos e às inovações que são requisitadas para a transformação da realidade produtiva, ambiental, política e social dos povos do campo.

A educação do campo deve ser vista não apenas como modalidade de ensino, mas também como uma política pública que garanta a população camponesa os mesmos direitos educacionais garantidos à população urbana já que, no decorrer da história, essa modalidade educacional sempre foi deixada em segundo plano. Não houve um investimento significativo pelos representantes governamentais para que tivesse uma educação do campo condizente com a cultura e identidade do povo camponês.

Além disso, não houve legislações específicas que garantissem o direito à educação de qualidade à população camponesa. Isso significa que esteve presente em nosso sistema educacional uma educação urbanizadora em que a cultura urbana era introduzida nas práticas educacionais camponesas sem qualquer significação para essa parcela da população.

As diretrizes que regulamentam a educação do campo introduzem no contexto escolar camponês práticas educacionais condizentes com a realidade, a cultura e a identidade do povo do campo. Possibilitam, assim, um resgate 
cultural da população camponesa, como também permite que essa população permaneça em seu espaço rural, sem se deslocar para os centros urbanos a fim de melhores condições de vida, sendo realmente uma educação do campo e no campo.

As Diretrizes Operacionais para a Educação Básica nas Escolas do Campo definem, em seu artigo $2^{ }$, parágrafo único, a identidade dessas escolas.

\begin{abstract}
A identidade da escola do campo é definida pela sua vinculação às questões inerentes a sua realidade, ancorando-se na temporalidade e saberes próprios dos estudantes, na memória coletiva que sinaliza futuros, na rede de ciência e tecnologia disponível na sociedade e nos movimentos sociais em defesa de projetos que associem as soluções exigidas por essas questões à qualidade social da vida coletiva no país (BRASIL, 2002, p. 1)
\end{abstract}

Embora haja o reconhecimento das peculiaridades próprias do campo (como sua identidade, temporalidade, saberes e memória coletiva) na Resolução de 2002, e mesmo fortalecida pela Lei n 9.394/96 em seus artigos 23, 26 e 28, em que se contempla a diversidade do campo nos diversos aspectos (social, cultural, político, econômico, de gênero, geração e etnia), percebemos que essas escolas ainda permanecem centradas num modelo de educação urbana.

Esses fatores nos provocam a redirecionar o olhar à cultura, às características, às necessidades e aos sonhos dos que vivem nesses meios em busca da democratização do ensino, por meio da efetivação das políticas públicas para essa modalidade educativa.

Atualmente, a legislação educacional brasileira apresenta uma vasta base legal - conquistada com a participação efetiva dos movimentos sociais do campo - para a instituição de políticas públicas diferenciadas ao atendimento escolar das pessoas que vivem e trabalham no meio rural, como o Decreto 7352/2010 que, em seu artigo 1ํㅡ, conceitua população do campo e escola do campo.

Populações do campo: agricultores familiares, os extrativistas, os pescadores artesanais, os ribeirinhos, os assentados e acampados da reforma agrária, os trabalhadores assalariados rurais, os 
quilombolas, os caiçaras, os povos da floresta, os caboclos e outros que produzam suas condições materiais de existência a partir do trabalho no meio rural.

Escola do campo: aquela situada em área rural, conforme definida pela Fundação Instituto Brasileiro de Geografia e Estatística - IBGE, ou aquela situada em área urbana, desde que atenda predominantemente a populações do campo (grifo nosso) (BRASIL, 2010, p.1).

A partir do Decreto, percebe-se a necessidade de uma educação que respeite e valorize a cultura da população campesina, a fim de que os alunos construam suas identidades de forma positiva e valorativa, estando essa escola na área rural ou urbana, como cita o Decreto acima.

O Decreto no $7352 / 2010$ surge em resposta às demandas sociais em nome de uma educação do campo que estivesse de acordo com a realidade do povo camponês. Ele dispõe sobre a política de educação do campo e o Programa Nacional de Educação da Reforma Agrária, o PRONERA.

$O$ art. $1^{\circ}$ estabelece que a União tem o dever legal de ampliar a política da educação do campo e que os Estados, Municípios e Distrito Federal colaborarão com o desenvolvimento dessa política. Importante dizer que esse Decreto acaba evidenciando como política de educação do campo não apenas a educação básica (da educação infantil ao ensino médio), mas também determina como política o ensino superior para essa parcela da população.

Sem dúvida, tal determinação é de suma importância, pois possibilita à população da área rural chegar ao ensino superior, dando condições e possibilidades para que as pessoas que vivem no campo possam ter uma qualificação profissional de âmbito superior.

O parágrafo $4^{\circ}$ do Art. $1^{\circ}$ do mesmo Decreto determina a oferta de formação inicial e continuada de profissionais da educação, bem como estabelece a garantia de dar condições de infraestrutura e transporte escolar para a população camponesa. Isso porque muitos dos que estudam no meio rural são impedidos de estudar pela falta de um transporte que leve os alunos até a escola. E, não raras vezes, os veículos utilizados para o transporte não possuem o mínimo de segurança aos alunos.

Schwendler (2005) retrata bem a situação calamitosa que envolve o transporte escolar nas áreas rurais. 
Devido às distâncias entre os moradores e as próprias comunidades onde passa o transporte escolar, os educandos são obrigados a levantar muitas vezes de madrugada e/ou ficarem horas no trajeto entre sua casa e a escola. Assim, ficam à margem do cotidiano da vida e dos valores do campo. Quando educandos são retirados do seu contexto para estudar (por meio da nuclearização na cidade), são afastados de suas raízes culturais, de sua identidade (SCHWENDLER, 2005, p.35).

Nesse sentido, constata-se que o ideal seria a escola se situar na própria zona rural onde vivem os alunos (educação no campo), para que estes não precisassem se deslocar, perdendo tempo e, muitas vezes, arriscando suas vidas e integridade física. Além disso, evitaria que os alunos fossem afastados de sua cultura e se tornassem vítimas de preconceitos das pessoas que moram no meio urbano, por considerarem as pessoas do campo como atrasadas, caipiras e com uma cultura ultrapassada.

Nesse contexto, é importante ressalvar que o Estatuto da Criança e do Adolescente (Lei 8069/90), em seu artigo 53, determina que a criança e 0 adolescente têm o direito ao acesso à escola pública e gratuita próxima de sua residência. Desse modo, tal preceito também deve ser assegurado aos alunos do campo.

O parágrafo $4^{\circ}$ do artigo $1^{\circ}$ do Decreto ainda determina garantia de "materiais didáticos, equipamentos, laboratórios, biblioteca e área de lazer e desporto adequados ao projeto político pedagógico e em conformidade com a realidade local e a diversidade das populações do campo".

O art. $2^{\circ}$ do Decreto estabelece cinco princípios da educação do campo:

I - respeito à diversidade do campo em seus aspectos sociais, culturais, ambientais, políticos, econômicos, de gênero, geracional e de raça e etnia;

II - incentivo à formulação de projetos político-pedagógicos específicos para as escolas do campo, estimulando 0 desenvolvimento das unidades escolares como espaços públicos de investigação e articulação de experiências e estudos direcionados para 0 desenvolvimento social, economicamente justo $e$ ambientalmente sustentável, em articulação com 0 mundo do trabalho;

III - desenvolvimento de políticas de formação de profissionais da educação para 0 atendimento da especificidade das escolas do campo, considerando-se as condições concretas da produção e reprodução social da vida no campo;

IV - valorização da identidade da escola do campo por meio de projetos pedagógicos com conteúdos curriculares e metodologias adequadas às reais necessidades dos alunos do campo, bem como 
flexibilidade na organização escolar, incluindo adequação do calendário escolar às fases do ciclo agrícola e às condições climáticas:

$\mathrm{V}$ - controle social da qualidade da educação escolar, mediante a efetiva participação da comunidade e dos movimentos sociais do campo (BRASIL, 2010).

Assim, de acordo com as leis analisadas, constata-se que, atualmente, a educação do campo possui um arcabouço jurídico consistente e significativo para que as pessoas que vivem no campo possam ter uma educação com qualidade. Isso significa uma educação condizente com seus interesses e necessidades. Entretanto, para que essa qualidade ocorra de fato, é necessário que as determinações legais sejam colocadas em práticas e que não fiquem apenas no papel. Somente com a aplicação dessas determinações legais haverá o respeito à identidade e à dignidade do povo camponês.

Mas não basta criar propostas educacionais que atendam exclusivamente à população do campo sem que haja a preocupação de prescrever suas características históricas e culturais. É preciso, sim, formular políticas públicas que atendam ao povo do campo de forma diferenciada no âmbito educacional, sem que esse sofra mudanças comportamentais e precise acompanhar a visão urbana necessária, porém não exclusiva.

[...] é a luta do povo por políticas públicas que irão garantir o seu direito à educação e a uma educação que seja no e do campo. No: o povo tem direito a ser educado no lugar onde vive; Do: o povo tem direito a uma educação pensada desde o seu lugar e com a sua participação, vinculada à sua cultura e às suas necessidades humanas e sociais (CALDART 2004, p. 149-150).

Nesse mesmo contexto, Fernandes, Cerioli e Caldart (2005, p. 27) dizem que "não basta ter escolas no campo; queremos ajudar a construir escolas do campo, ou seja, escolas com um projeto político-pedagógico vinculado às causas, aos desafios, aos sonhos, à história e à cultura do povo trabalhador do campo"

Frente a esses fatos que estão desenhando uma nova pedagogia para 0 povo do campo, Caldart (2004, p. 151) coloca que 
[...] um basta aos 'pacotes' e à tentativa de fazer das pessoas que vivem no campo instrumentos de implementação de modelos que as ignoram ou escravizam. Basta também desta visão estreita de educação como preparação de mão-de-obra e a serviço do mercado. Queremos participar diretamente da construção do nosso projeto educativo; queremos aprender a pensar sobre a educação que nos interessa enquanto seres humanos, enquanto sujeitos de diferentes culturas, enquanto classe trabalhadora do campo, enquanto sujeitos das transformações necessárias em nosso país, enquanto cidadão do mundo.

É nessa perspectiva que precisamos nos envolver como educadores e resgatar, por meio da luta pela qualidade da educação do campo e juntamente com nossa comunidade escolar, uma proposta pedagógica que venha ao encontro dos anseios da população campesina.

Diante do exposto, conclui-se que a educação do campo foi uma conquista dos movimentos sociais que pretendiam uma educação que estivesse de acordo com os interesses e as necessidades da população camponesa, para que o homem do campo tivesse orgulho de sua terra e de seus costumes. Isso significa construir, de forma positiva e significativa, a identidade do homem do campo sem tratá-lo como pessoa atrasada e submissa aos que vivem no meio urbano.

Portanto, a educação do campo surge em resposta aos movimentos sociais na busca por uma educação para todos os que moram no campo; na erradicação do analfabetismo; no resgate da cultura camponesa subjugada e menosprezada; na valorização da agricultura familiar; na valorização da reforma agrária como instrumento importante para a conquista da terra; enfim, na busca pelos mesmos direitos educacionais cabíveis à parcela da população urbana.

\section{CONCLUSÃO}

As políticas públicas Por Uma Educação no/do Campo vêm se tornando extremamente importantes para os povos do campo. Elas são o resultado de luta por uma escola que defenda, reconheça, fortaleça e garanta o direito a uma educação vinculada às suas necessidades sociais, e que seja pautada nos interesses da comunidade, com as adaptações necessárias à vida no campo. 
Convém destacar que, para ser uma escola do campo, não basta possuir leis. É preciso se tornar prática, pois as leis, por si só, não garantem a efetivação da Educação do Campo. Como também não basta a escola estar no campo, pois mesmo estando na área urbana, o que determina a modalidade da educação a ser oferecida é sua clientela.

Com a pesquisa realizada foi possível perceber que é necessário romper com o paradigma binário educação campo-cidade, compreendendo esses dois espaços como complementares, principalmente quando a Educação do Campo deve ser oferecida no contexto urbano.

$\mathrm{Na}$ visão de uma relação híbrida, em que o campo não vive sem a cidade, que não vive sem o campo, é preciso transitar entre ambas as culturas e interesses, já que os diferentes espaços carregam traços identitários distintos e, ao mesmo tempo, complementares. É, sobretudo, inegável o fato de que o funcionamento de um espaço depende do outro. Por isso, não devemos polarizar a dicotomia das relações existentes entre campo-cidade, mas problematizá-las, sem deixar que a educação perca de vista os processos identitários e culturais. Nesse sentido, precisamos discernir o papel da escola do campo na cidade, de modo a tornar seu ensino uma tarefa específica, a partir de uma proposta adequada que atenda aos alunos de várias culturas e múltiplas identidades.

Batista (2003) diz que, para educação do campo tornar-se uma realidade possível, é preciso esquematizar uma analogia entre educação campo-cidade. Nas proposições do autor, para fazer uma distinção, devemos considerar 0 papel da escola nas áreas rurais e urbanas, de modo a tornar o ensino uma tarefa específica, sem perder de vista as diferentes identidades culturais.

Nesse sentido, uma proposta de educação significativa consiste no desenvolvimento de um modelo de currículo que integre a prática educativa à prática social. Assim, a educação deve servir aos interesses da comunidade e desempenhar uma prática sociocultural de conteúdos, valores e vivências refletidas no currículo escolar. 


\section{REFERÊNCIAS}

ALMEIDA, Rosmeire A. de. (Re) criação do campesinato, identidade e distinção: a luta pela terra e o habitus de classe. São Paulo: Editora UNESP, 2006.

ARROYO, Miguel. FERNANDES, Bernardo Mançano. A Educação Básica e o Movimento Social no Campo (Por uma Educação do Campo). Brasília, 1999.

BATISTA, Francisca Maria Carneiro. Educação Rural: das experiências à política pública. Brasília, DF: Editorial Abaré, 2003.

BRASIL. (1996). Lei o 9.394, de 20 de dezembro de 1996. Estabelece as Diretrizes e Bases da Educação Nacional. Diário Oficial da União, Brasília, 23 dez. 1996.

. (2002). Resolução CNE/CEB no 1, de 3 de abril de 2002. Institui diretrizes operacionais para a educação básica das escolas do campo. Brasília.

. (2010). Resolução CNE/CEB no 7, de 14 de dezembro de 2010. Fixa diretrizes curriculares nacionais para o ensino fundamental de 9 (nove) anos. Brasília.

CALDART, Roseli Salete. Pedagogia do movimento sem terra. São Paulo: Expressão Popular, 2004.

Roseli Salete et al (Org.). Dicionário de Educação do campo. Rio de Janeiro: Expressão Popular, 2012.

CERIOLI, Paulo Ricardo; CALDART, Roseli Salete. "Primeira Conferência Nacional 'Por uma educação básica do campo': texto preparatório". In: ARROYO, Miguel Gonzalez; CALDART, Roseli Salete; MOLINA, Mônica Castagna. Por uma educação do campo. Petrópolis: Vozes, 2005.

FERNANDES, B. M. MOLINA, M. C. \& JESUS, S. M. S. A. (org.). Contribuições para a construção de um projeto de educação do Campo Brasília, DF: 18 Articulação Nacional Por uma Educação Básica do Campo, 2004.

. Educação do Campo: Notas para uma análise de percurso. In: MOLINA, M. Castagna (org.) Educação do Campo e Pesquisa II: questões para reflexão. Molina, M. Castagna, MDA, MEC, BRASíLIA, 2010. 
LEITE, S. C. Escola Rural: Urbanizações e políticas educacionais. São Paulo: Cortez, 1999.

MARTINS, José de Souza. Reforma agrária - o impossível diálogo sobre a História possível. Tempo Social; Rev. Sociol. USP, S. Paulo, 11(2): 97-128, out. 1999 (editado em fev. 2000).

. Os camponeses e a política no Brasil. Petrópolis, Vozes, 1981.

MELO, José Carlos de. Por entre as águas do sertão: currículo e educação ambiental das escolas rurais do Jalapão. São Paulo, 2011. Tese (Doutorado em Educação: Currículo), Pontifícia Universidade Católica de São Paulo (PUC $-\mathrm{SP})$.

ROSA, Daniela Souza da; CAETANO, Maria Raquel. Da educação rural à educação do campo: uma trajetória...seus desafios e suas perspectivas. Disponível em: http://www.portaltrilhas.org.br/download/biblioteca/da-educacaorural-a-educacao-docampo.pdf. Acesso em: 19 maio 2018.

SCHWENDLER, Sônia Fátima. Principais problemas e desafios da educação do campo no Brasil e no Paraná. In: Cadernos temáticos: educação do campo. Paraná. Secretaria de Estado da Educação. Superintendência da Educação. Departamento de Ensino Fundamental. Curitiba: SEED, 2005.

WANDERLEY, Maria de Nazareth B. Raízes históricas do campesinato brasileiro. XX Encontro Anual da ANPOCS. Anais... GT 17. Processos Sociais Agrários, Caxambu, MG. 1996. 